\title{
FACIAL NERVE AND TEMPOROMANDIBULAR JOINT FUNCTIONAL EVALUATION AFTER SUBCONDYLAR FRACTURES OSTEOSYNTHESIS BY RHOMBOID-PLATE VERSUS CONVENTIONAL MINIPLATES
}

Abdel Aziz Baiomy Abdullah Baiomy*, Shadia Abdelhameed Elsayed** and Mohamed Ashraf Abdelfattah ${ }^{* * *}$

\begin{abstract}
Aim : This study was conducted to assess the function of temporomandibular joint (TMJ) and the facial nerve after subcondylar fractures Osteosynthesis by three-dimensional 3D-rhomboid plate compared with conventional double miniplates.
\end{abstract}

Patient and methods: 20 patients suffering from unilateral displaced subcondylar fractures were divided randomly into two equal groups. Group, I was reduced and fixed by two miniplates while Group II was reduced and fixed by 3D-rhomboid plate. All patients were diagnosed according to Temporomandibular Dysfunction Diagnostic Research Criteria and classified according to the Helkimo Index. Facial nerve affection was assessed by Hause Brackmann facial nerve grading system. Radiographic evaluation was done using multi-slice CT and Orthopantomogram via condylar morphology scale (CMS) assessment. Postoperative occlusion and masticatory muscles were also assessed. All data collected and statistically analyzed.

Results: Results showed non statistically significant difference between groups, regarding mandibular mobility and occlusion status however, TMJ, muscular pain, facial nerve affection, and CMS parameters showed comparable values between both groups in favor of Rhomboid plate group.

Conclusion: From the results from the current study we can conclude that 3D-rhomboid plate had good functional TMJ and facial nerve outcomes in comparable to standard two miniplates in management of high subcondylar fracture.

KEY WORDS: subcondylar fractures; 3D rhomboid plate; miniplates; TMJ; facial nerve.

* Associate Professor of Oral and Maxillofacial Surgery, Faculty of Dental Medicine, Al-Azhar University, Assiut, Egypt.

** Associate Professor, Department of Oral and Maxillofacial Surgery, Faculty of Dental Medicine, for Girls Al-Azhar University.

*** Dentist at Hearing and Speech Institute General, Organization of Teaching Hospitals and Institutes, Cairo, Egypt. 


\section{INTRODUCTION}

The treatment of subcondylar fracture (open versus closed) is highly controversial ${ }^{[1]}$ and debate still present concerning the most acceptable method of fixation among maxillofacial surgeons who mostly prefer open treatment ${ }^{[2,3]}$. This fracture management varied between closed reduction with a period of maxillomandibular fixation (MMF) integrated with functional occlusal therapy and open reduction with several types of bone plates to give proper fixation for subcondylar fracture and prevent TMJ disorders, facial nerve injury, and occlusal disorders which may be occurred ${ }^{[4]}$. If subcondylar fractures aren't treated properly, the trauma can cause Temporomandibular joint disorders (TMJD), TMJ ankylosis, occlusal discrepancy, mandibular asymmetry, facial nerve injury and it may lead to severe impairment of the stomatognathic system ${ }^{[5]}$.

The closed conservative approach is easy and not invasive, however, it requires varying periods of MMF (1- 4 weeks) aided with elastic manipulation and it has several complications such as pain, ankylosis, derangement of the TMJ, in addition to the vertical ramus height shortage ${ }^{[6]}$. Accordingly, open reduction-internal fixation (ORIF) was used as another alternative modality to overcome these complications. ORIF gives proper anatomic reduction and immediate jaw function, as well as reconstruction of the vertical ramus height. Moreover, it is preferred in management of adult cases with a condylar displacement of $10-45^{\circ}$ or ramus shortening more than $2 \mathrm{~mm}^{[7-9]}$.

The main goal of surgical open Osteosynthesis for condylar neck fracture is to obtain good anatomic relationship and function without stability disturbances of the fixation devices during mechanical stresses arising during mastication forces which affected by the muscle pull action on the mandible ${ }^{[10,11]}$.

Clinical and biomechanical studies ${ }^{[12,13]}$ reported that two miniplates are the most acceptable procedure for fixation of subcondylar fractures. However, two miniplates are used mainly in cases with low fractures because they require the presence of a long proximal fractured segment. Therefore, several trials were developed to provide a three-dimensional bone plate such as delta and rhombic bone plates. They have a smaller size than two miniplates which allow fixation of the small remaining proximal segment. Thus, the design of 3D rhombic plate could enable fixation of even a higher subcondylar fracture with preservation on the facial nerve and TMJ system.

Most clinical studies ${ }^{[14,15]}$ had evaluated the efficacy of rhombic 3D plates incomparable with conventional double miniplates in the management of extracapsular subcondylar fractures from aspects of stability and density of bone at the fracture site. However, there are paucity of information assessing TMJ function and facial nerve affection after rhomboid $3 \mathrm{D}$ plate fixation. Therefore, in the current study, we used the retromandibular approach and the main parameters studied were TMJ function and the facial nerve weakness.

\section{PATIENTS AND METHODS}

The current study was a clinical comparative study carried out on a total number of twenty patients. All patients enrolled were suffering from unilateral displaced subcondylar fractures indicated for open reduction and fixed according to the random assignment before the operation with either 3D rhomboid or double conventional miniplates. The study conducted at the Department of Oral and Maxillofacial Surgery, Faculty of Dentistry, AlAzhar university-Assuit branch, Egypt over 4 years (October 2015 till October 2019). Patients signed informed consent after discussing all information about the surgery. The study was approved by the Al-Azhar University ethical committee and done following the Helsinki declaration of human research conduct. 


\section{Grouping:}

Patients were divided randomly into two equal groups according to the type of bone plate fixation.

- Group I (control group): included 10 patients with unilateral subcondylar fracture who fixed by two standard miniplates $2.0 \mathrm{~mm}$ (KLS Martin, Tuttlingen, Germany).

- Group II (study group): included 10 patients with unilateral subcondylar fracture who fixed by 3D rhomboid plate (KLS Martin, Germany).

\section{Inclusion criteria}

The study included medically fit (in term of American Society of Anesthesiologists (ASA)) dentate patients who didn't have any contraindication to the surgery, suffering from unilateral displaced extracapsular subcondylar fractures associated with any of the following Kent and Zide criteria ${ }^{[16]}$ for absolute and relative indications for open surgical approach such as dislocation into the middle cranial fossa or EAM, lateral condylar displacement, difficulty in obtaining occlusion and gross contamination of the wound or presence of a foreign body.

\section{Exclusion criteria:}

We excluded from the current study, patients with comminuted condylar fracture, or bilateral condylar fractures, infected wound and patients who had a history of any TMJ internal derangement.

\section{Preoperative phase:}

The preoperative phase included personal history, medical history , history of trauma, and extraoral and intraoral clinical examination. Radiographic examination included Orthopantomogram (OPG), and CT scans in the three planes with $3 \mathrm{D}$ reconstruction, and all routine laboratory investigations were done for all patients ( Figure .1).

\section{Operative phase:}

The operative team included two fixed maxillofacial surgeons for all the studied patients. Fracture sites were exposed through a modified retromandibular approach. The fractured proximal segment was reduced and fixed with a rhomboid plate or two miniplates,
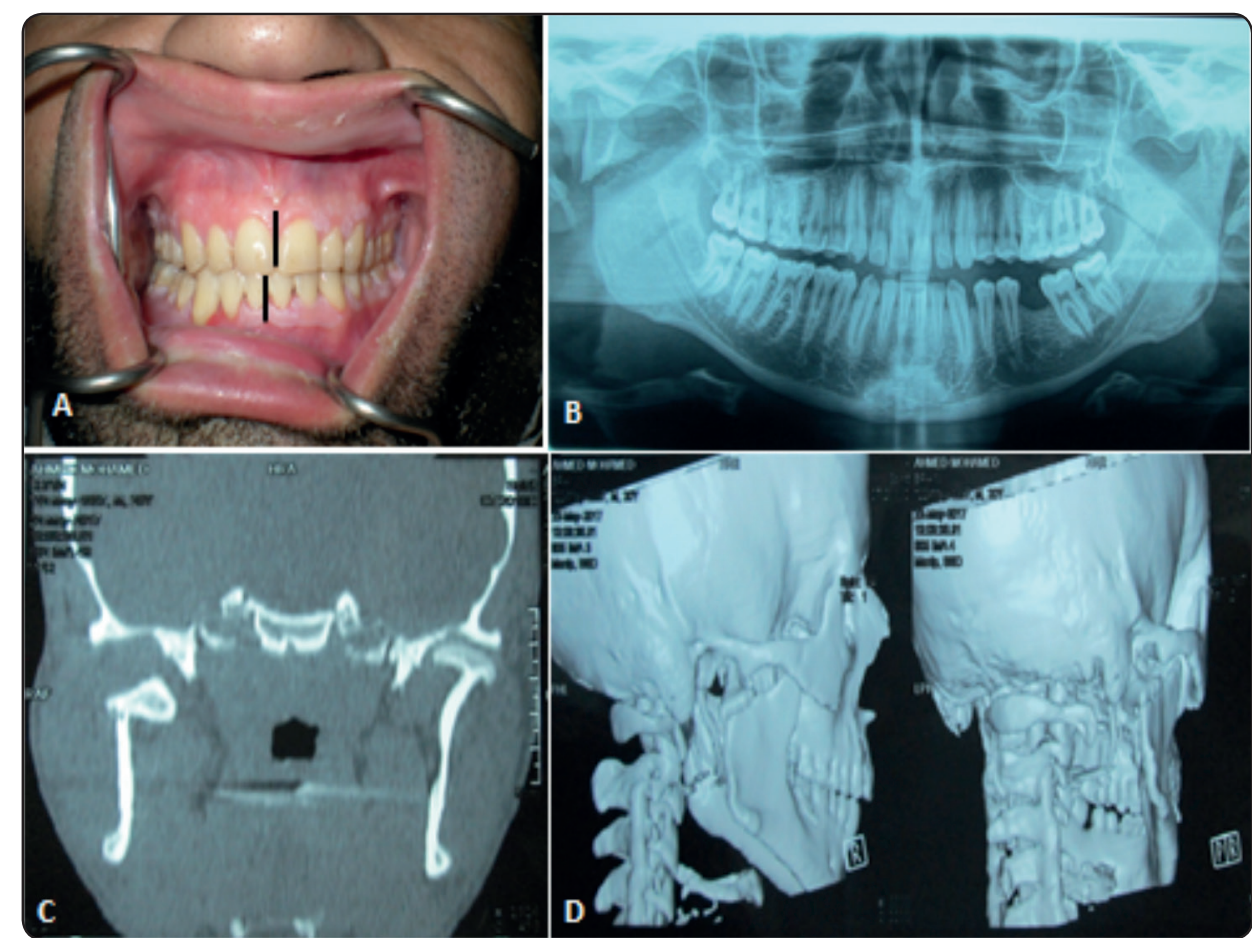

Fig. (1) (a) preoperative intraoral photograph showing deranged occlusion. (b) preoperative OPG, (c) Preoperative coronal, and 3D CT showing unilateral right subcondylar fracture. 


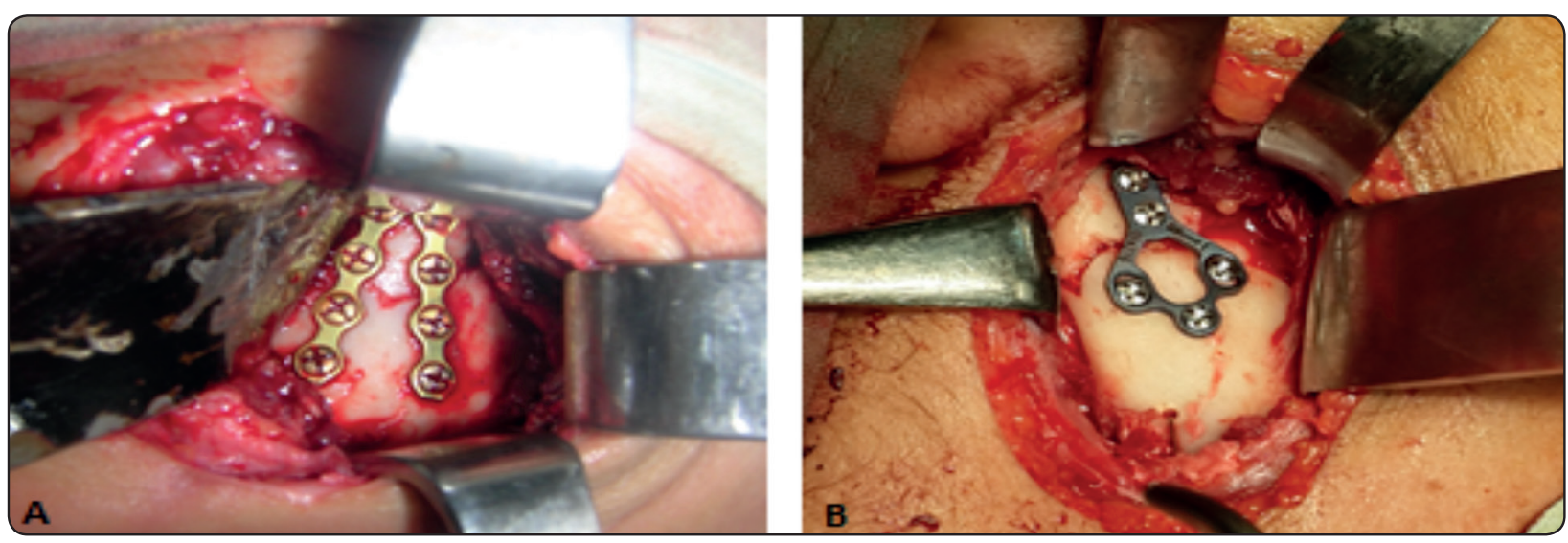

Fig. (2) Intraoperative photographs showing fixation using (A) Two standard miniplates $2.0 \mathrm{~mm}$ in group I and (B) Rhomboid 3D plate in group II.

- In group II, the 3D rhomboid plate was adapted to the condylar curvature. The plate was secured in place using 5 (2.0mm width and $7 \mathrm{~mm}$ length) screws (Figure 2a).

- In group I, double miniplates were used. One plate was adapted parallel to the posterior border of the ramus, while the other plate was adapted along the anterior border of the condyle. Four screws $(2.0 \mathrm{~mm}$ width and $7 \mathrm{~mm}$ length) were used for securing each plate (Figure 2b). The MMF was released to check proper occlusion then the wound was closed in layers. All concomitant fractures were fixed via open reduction internal fixation technique.

\section{Postoperative phase care:}

Antibiotic schedule was prescribed post-operatively for 5 days, Amoxicillin/Clavulanate potasium 1 gm IV twice daily, (Augmentin, GlaxoSmithKline, Brentford, London). In addition to anti-inflammatory drug, Diclofenac sodium $75 \mathrm{mg}$ IV (Cataflam, Novartis, Basel, Switzerland) were used for 5 days postoperatively. Oral hygiene maintenance using $0.2 \%$ Chlorhexidine mouth wash was advised to all patients.
Skin sutures were removed one week postoperatively and joint function was checked. Heavy elastics were used for 3-days postoperatively followed by light elastics for another 4-days to limit interfragmentary movements and minimize postoperative pain. Arch bars were removed 7-day postoperatively.

\section{Postoperative clinical evaluation:}

Follow-up examinations were performed immediately postoperatively and after 1 week, 3 months, and 6 months. The assessment included the following points: Evaluation of occlusal status to detect if it was stable or deranged. Also, TMJ and muscular pain were evaluated through palpation of the TMJ, masticatory muscles and preauricular area using the visual analog scale (VAS) with endpoint marked score 0 for (no pain) and score 10 for (worst pain $)^{[17,18]}$.

Temporomandibular Dysfunction was assessed through an examination using the Research Diagnostic Criteria for Temporomandibular Dysfunction (RDC/TMD) ${ }^{[19,20]}$ and patients were also classified according to the Helkimo Index ${ }^{[21]}$.

Assessment of facial nerve function was performed through clinical diagnosis and House Brackmann Facial Nerve Grading System ${ }^{[22,23]}$. 


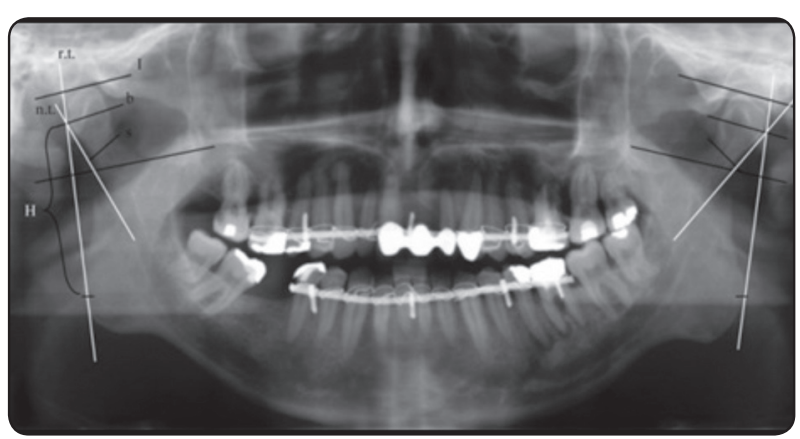

Fig. (3) Tracing of OPGs for analysis of CMS and ramal height. $\mathrm{H}$ ramus height; n.t. neck tangent; r.t. ramus tangent; b broadest condylar dimension, perpendicular to r.t.; $\mathrm{s}$ smallest condylar dimension, perpendicular to n.t

\section{Radiographic assessment}

Computed tomograms with 3D images were obtained and checked for adequate reduction of the fracture segment and condylar position. The Ramal height was also measured on OPGs, before and after surgical reduction of the fracture using the condylar morphology scale method (CMS) ${ }^{[21,24]}$ ( Figure 3).

\section{Statistical analysis}

The study variables data were collected and coded using the statistical package of social sciences (SPSS, version 24, Chicago, Illinois, USA) program for statistical analysis. Descriptive and inferential analyses were performed using t-test and chi-square test for association. P-value was set at or below 0.05 to define significance.

\section{RESULTS}

Twenty patients suffered from unilateral subcondylar fractures were included in the present study and their age ranged between 18 and 44 years. Males predominated with a percentage of $75 \%$ of the cases. Eleven fractures were classified as high subcondylar fractures and 9 as low subcondylar fractures. 7 fractures were at right side and 13 at left side. Concomitant associated fractures occurred as follows: $45 \%$ were parasymphyseal fractures; $25 \%$ were angle fractures; $15 \%$ were body and angle fractures, and $15 \%$ were body fractures only.

Intraoperative, the 3D Rhomboid plate was superior in time-saving and feasibility of its manipulation. Postoperatively, all fractures healed uneventfully without complications as infection or plate loosening. The hypertrophic scar was seen as late manifestation of wound healing in two cases of group I, where plastic revision was done, and silicone creams or patches were initiated.

\section{Occlusion status:}

All patients had occlusal derangement preoperatively. During the first postoperative week, 3 patients in group II and 2 patients of group I had mild occlusal discrepancies which were corrected by using intermaxillary elastics for 10 days. At one month later, all patients had a normal occlusion or no discrepancy except one case in group II who had mild occlusal discrepancies which were corrected by using intermaxillary elastics for another10 days. There was a statistically significant difference between preoperative and postoperative occlusion at the end of the study in both groups with a p-value of 0.007 in group I and 0.009 in group II. Satisfactory occlusion was obtained at the end of the study for all patients without any statistically significant difference between both groups.

\section{RDC/TMD measurements:}

All clinical findings were acceptable in all patients of both. Regarding mandibular movement assessment, the mean values of maximal active inter-incisal opening, ipsilateral, contralateral and protrusive movement in group I were 48.5, 11.5, 11.2 , and $6.7 \mathrm{~mm}$ and 49.2,12.1, and 10.8,5.9 $\mathrm{mm}$ in group II without any significant difference between both groups (Table 1).

\section{Helkimo index assessment:}

The Helkimo index evaluation ranged between (no to severe dysfunction). $40 \%$ in group I and $50 \%$ in group II, classified as Di0 (Free of symptoms) according to Helkimo Index while, 30\% of patients in group I \& II were classified as Di1 (mild dysfunction), and 20\% of patients in both groups as DiII (moderate dysfunction). 10\% of cases in group I showed severe dysfunction while no one in group II showed severe dysfunction. 
TABLE (1) Descriptive and inferential Statistics for the RDC/TMD at 6 months comparing both groups.

\begin{tabular}{|l|c|c|c|c|c|c|c|}
\hline & \multicolumn{3}{|c|}{ Group I (n=10) } & \multicolumn{3}{c|}{ Group II (n=10) } & \multirow{2}{*}{$P$} \\
\cline { 2 - 7 } & Mean (mm) & Range & \pm SD & Mean (mm) & Range & \pm SD & \\
\hline Unassisted mouth opening with an overbite & 44.7 & $26.8-61.5$ & 9.4 & 45.3 & $27.0-62.0$ & 9.6 & 0.23 \\
\hline Maximal unassisted mouth opening with overbite & 48.5 & $30.0-62.0$ & 9.5 & 49.2 & $31-61.9$ & 9.3 & 0.17 \\
\hline Assisted mouth opening with overbite & 48.5 & $33.5-61.8$ & 9.4 & 49.4 & $34.0-62.0$ & 9.1 & 0.31 \\
\hline Laterotrusion right & 11.5 & $2.5-18$ & 3.7 & 12.1 & $3.4-19$ & 3.9 & 0.33 \\
\hline Laterotrusion left & 11.2 & $2.7-17.5$ & 4.4 & 10.8 & $1.9-14.9$ & 4.5 & 0.10 \\
\hline Protrusion & 6.7 & $1.5-12$ & 3.5 & 5.9 & $0.2-9.7$ & 3.7 & 0.14 \\
\hline Overjet & 2.7 & $0.0-5.0$ & 1.6 & 2.5 & $0.0-5.3$ & 1.5 & 0.19 \\
\hline Overbite & 3.94 & $0.1-7.9$ & 2.7 & 3.8 & $0.2-8.0$ & 2.9 & 0.41 \\
\hline
\end{tabular}

** High statistically significant when $p \leq 0.01$

* Statistical significance when $p \leq 0.05$

\section{TMJ and masticatory muscle Pain}

Statistically, the analysis presented a highly significant difference along the study period between preoperative and postoperative follow-up periods in both groups. Statistical significant differences were demonstrated between both groups at one and three months in favor of the rhomboid group (Table 2).

TABLE (2) TMJ \& Muscular pain after palpation

\begin{tabular}{|c|c|c|c|c|}
\hline & $\begin{array}{c}\text { Group I } \\
(\text { Mean } \pm \text { SD })\end{array}$ & $\begin{array}{c}\text { Group II } \\
(\text { Mean } \pm \text { SD) }\end{array}$ & $\mathbf{t}$ & $\begin{array}{c}P \\
\text { value }\end{array}$ \\
\hline Preoperative & $7.3 \pm 0.8$ & $7.1 \pm 2.2$ & 0.000 & 1.0 \\
\hline $1 \mathrm{w}$ & $8 \pm 0.5$ & $6.8 \pm 0.8$ & -1.12 & 0.11 \\
\hline $1 \mathrm{~m}$ & $4.2 \pm 1.0$ & $3.1 \pm 0.8$ & 1.30 & $0.055 *$ \\
\hline $3 m$ & $2.7 \pm 0.7$ & $1.1 \pm 0.2$ & 1.60 & $0.045^{*}$ \\
\hline $6 \mathrm{~m}$ & $0.5 \pm 0.7$ & $0.4 \pm 0.5$ & 0.500 & 0.217 \\
\hline $\mathbf{T}$ & 2.3 & 2.8 & & \\
\hline$P$ value & $0.000 * *$ & $0.001 * *$ & & \\
\hline
\end{tabular}

***High statistically significance when $p \leq 0.01$

* Statistically significance when $p \leq 0.05$

\section{Facial nerve weakness}

In the current study, in group I, three patients developed facial nerve weakness versus only one patient in group II. One out of the three patient of group I, had weakness only in the buccal branch of the facial nerve at first week after surgery which was recovered after one month. The Two patients who had weakness in both buccal and marginal mandibular branches recovered (one at third month after surgery in group II and one at six months in group I). There is a significant difference between both groups in the mean of recovery time, where the facial nerve weakness continued for 3 months in group II and 6 months in group I. At the end of the study, no permanent facial nerve weakness noted except in one patient in group I, which was observed during active mouth puckering and downward movement of the affected corner of the mouth (Table 3).

\section{Radiographic findings:}

Preoperative CT with 3D images for both groups showed displaced fractured fragment in all enrolled cases. Four patients showed severely 
TABLE (3) Assessment of Facial nerve function:

\begin{tabular}{|c|l|c|c|c|c|c|}
\hline \multirow{2}{*}{ Group I } & \multicolumn{1}{|c|}{ I weeks } & 1 month & 3month & 6month & P value \\
\cline { 2 - 7 } & Mormal Function & $70 \%$ & $80 \%$ & $80 \%$ & $90 \%$ & \multirow{2}{*}{$0.007 *$} \\
\hline \multirow{2}{*}{ Group II } & Normal Function & $90 \%$ & $90 \%$ & $100 \%$ & $100 \%$ & \multirow{2}{*}{$0.009 *$} \\
\cline { 2 - 6 } & Mild dysfunction & $10 \%$ & $10 \%$ & $0 \%$ & $0 \%$ & \\
\hline
\end{tabular}

** High statistically significance when $p \leq 0.01$

* Statistically significance when $p \leq 0.05$

TABLE (4) Comparison between preoperative and postoperative ramus length and angulation

\begin{tabular}{|c|c|c|c|}
\hline & & $\begin{array}{l}\text { The difference in ramus length Mean } \pm \text { SD } \\
\qquad[\mathrm{mm}]\end{array}$ & $\begin{array}{c}\text { Angulation } \\
\text { Mean } \pm \text { SD [degrees] }\end{array}$ \\
\hline \multirow{2}{*}{ Group I } & Preoperative & $8.4 \pm 4.2 \mathrm{~mm}$ & $21.8 \pm 19.2^{\circ}$ \\
\hline & Postoperative & $-0.2 \mathrm{~mm} \pm 1.4 \mathrm{~mm}$ & $0.0 \pm 1.2^{\circ}$ \\
\hline \multirow[b]{2}{*}{ Group II } & Preoperative & $8.6 \pm 3.8 \mathrm{~mm}$ & $24.3 \pm 16.6^{\circ}$ \\
\hline & Postoperative & $-0.1 \mathrm{~mm} \pm 1.1 \mathrm{~mm}$ & $0.0 \pm 1.3^{\circ}$ \\
\hline
\end{tabular}

displaced fractures. 13 cases had medial tilting of the fractured condyle in the coronal plane, and 3 cases observed in the lateral direction. $60 \%$ of cases showed upper fragment displacement toward an anterior direction during the examination of the sagittal plane, and $40 \%$ of the cases showed anteroposterior displacement toward the posterior direction. Immediate postoperative CT with threedimensional reconstructed images at one week showed a proper anatomic reduced position of the fragments in both groups (Figure 4).

Measurements on OPG showed that ramal height regained in all cases, and no case of condylar resorption was observed. Statistical analysis of the difference in ramal length and angulation means of showed a highly significant difference between values before and after open reduction in group II. and also showed a statistically significant difference between values before and after open reduction in group I. The average postoperative ramus height shortening compared with the intact side was less than $-0.2 \mathrm{~mm}$ in group I and less than $-0.1 \mathrm{~mm}$ in group II. This result showed a more accurate anatomical reduction of the fractured bone in group II than group I (Table 4). 

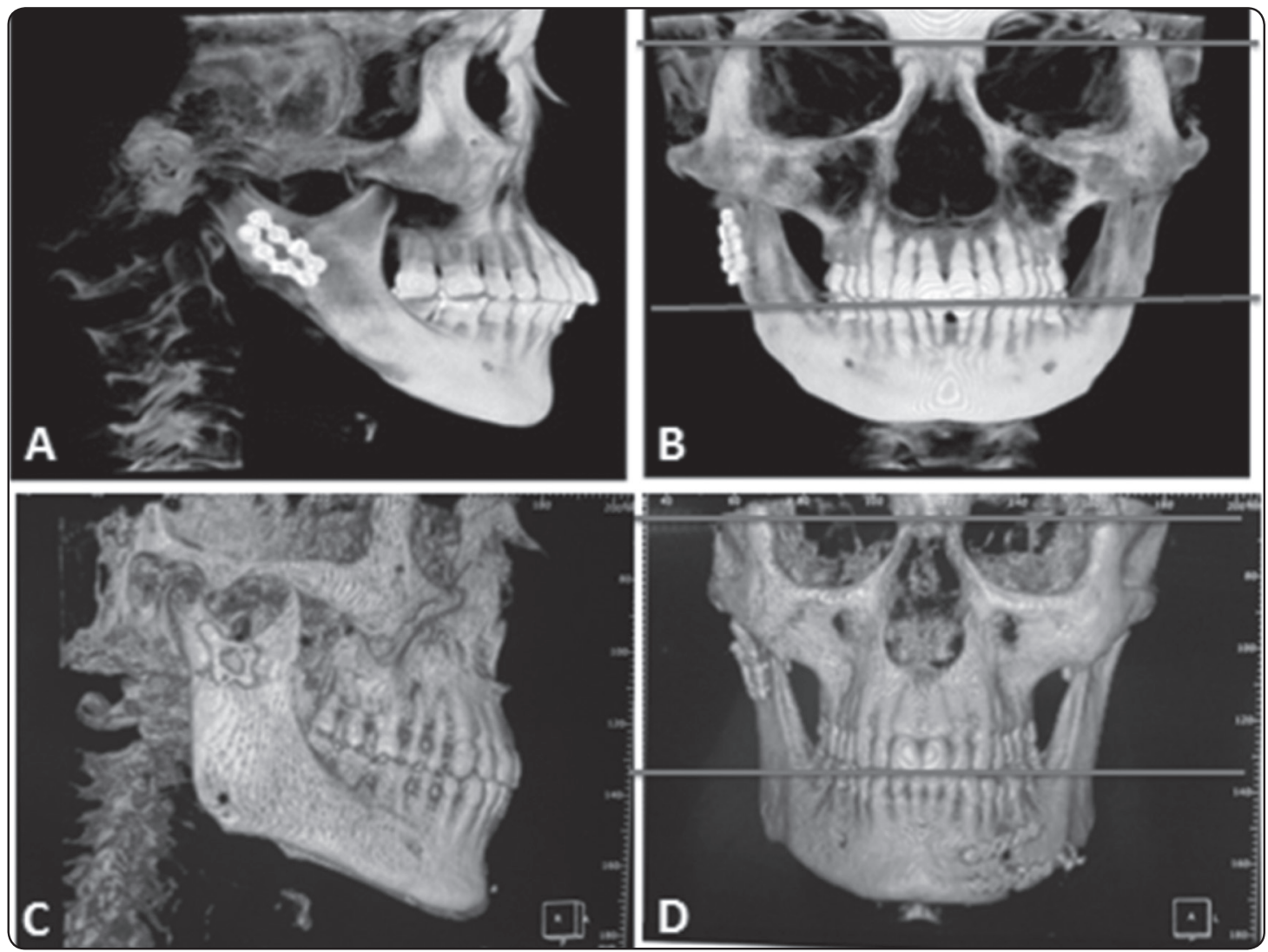

Figure 4. Postoperative (A \&C) lateral and (B \&D) anterior aspect 3D CT at one week showing bone reduction and occlusion plane in group I and group II.

\section{DISCUSSION}

The present study was an attempt for functional and radiographic evaluation and assessment of TMJ and facial nerve function after three-dimensional rhomboid bone plate fixation compared to double miniplates in the management of extracapsular subcondylar mandibular fractures.

One of the most common subjects that have generated more discussion and controversy in craniofacial surgery field is the management of subcondylar fractures. Improper treatment of subcondylar fracture could lead to several TMJ problems, facial nerve affection and occlusion derangement ${ }^{[25,26]}$.

There is still controversy regarding the choice between open and closed treatment ${ }^{[9,25,27]}$. The classical indication for ORIF requires that the clinician consider the degree of segment displacement and the functional occlusion status.

Recently, the risk of the seventh cranial nerve injury and TMJ disorders can be minimized with limited extraoral surgical approach for fracture site to preserve the anatomical structures such as TMJ, musculature, and facial nerve and through proper selection of the small size hardware type ${ }^{[27]}$. Some clinical studies consider double miniplates as a standard tool for fixation of the subcondylar fracture. However, the use of two miniplates had some drawbacks such as higher cost of hardware, longer operation time, and aggressive soft tissue retraction increasing the risk of facial nerve injury and TMJ trauma, in addition to some technical difficulty especially in cases with high subcondylar fractures, severely displaced fractures, and small proximal segment fractures. ${ }^{[12,25,28]}$. 
Tremendous revolutions in bone Osteosynthesis devices appeared in the recent years and one of these revolutions is the three-dimensional plate's designs. The three-dimensional rhomboid plate used in the present study act as a dual compression and tensile plate at the same time with the advantage of using only two screws in the proximal far segment which facilitate fixation of high subcondylar fractures with a gained more stable fixation than the semi-rigid double miniplate system ${ }^{[15]}$.

The results of the current study go in accordance with many other studies done using other threedimensional delta and rhomboid plates. All patients in both groups healed uneventfully without any encountered complications as infection or plate loosening ${ }^{[4,29,30]}$.

Regarding occlusion status, all patients in both groups had satisfactory occlusion at the end of the present study without any statistically significant difference between both groups consistent with findings of Ellis et $\mathrm{al}^{[30]}$.

RDC/TMD clinical examination showed that no patient presented with TM dysfunction after a postoperative period of at least 6 months without a significant difference between both groups. However, Helkimo index revealed that $10 \%$ of cases in group I showed severe dysfunction. Also, VAS of TMJ and muscular pain during palpation demonstrated statistically significant differences between both groups at one and three months.

These results of the current study on the facial nerve affection can be explained by the effect of aggressive soft tissue retraction during adaption of two miniplates in group I especially in high subcondylar fractures patients. Retraction injury leading to neuropraxia recovered earlier than a more severe injury like axonotemesis and this explanation agreed with the results of Dan Shi et al, study ${ }^{[31]}$. Also, our results go in agreement with the conclusion of Ellis ${ }^{[30]}$ article and the results of Veras et $\mathrm{al}^{[21]}$ about complications of mandibular condylar fracture.
At the end of the study, our results presented that no permanent facial nerve weakness noted except in one patient in group I. There is a statistically significant difference between groups in the mean of recovery time, as the weakness of facial nerve continued for 3 months in group II and 6 months in group I. In the present study, patient who had severe medially displaced fractures had prolonged recovery time. Similar results were found by Bhutia et al ${ }^{[32]}$ and Dan Shi et al ${ }^{[31]}$ due to operation time and retraction forces of soft tissue which could result in neuropraxia of the facial nerve.

Postoperative CT with three-dimensional reconstructed images for both groups showed a proper anatomical reduction of fractured segments. While CMS on OPG demonstrated that the average postoperative shortening of the ramus height compared with the intact side was less than -0.2 $\mathrm{mm}$ in group I and less than $-0.1 \mathrm{~mm}$ in group II. There was a more accurate anatomical reduction of fractured bone in group II than group I. This result matched with the conclusions of Kozakiewicz et al ${ }^{[15]}$ and Costa $^{[33]}$ studies who stated (that although finite element studies proved the superiority of two miniplates over all other hardware designs, threedimensional plates show clinically comparable outcomes, with easier application, less cost, and shorter fixation time). However, this goes in contrary to the results of $\mathrm{kang}^{[4]}$ study that concluded that "the use of two correctly positioned plates for the stabilization of subcondylar fractures is currently the best solution to provide stable Osteosynthesis in subcondylar fractures".

\section{CONCLUSION}

From the results of the present study, we can conclude that $3 \mathrm{D}$ rhomboid plate reconstructs the ascending ramus height and gives excellent TMJ functional results with decreased probability of facial nerve affection. Moreover, it offers less operative time. 


\section{FUND}

This research did not receive any specific grant from funding agencies in the public, commercial, or not-for-profit sectors.

Conflict of Interest: The authors declare that they have no conflict of interest.

\section{REFERENCES}

1. Gassner R, TuliT, Hachl O, Rudisch A UH. Craniomaxillofacial trauma: a 10-year review of 9543 cases with 21067 injuries. J Craniomaxillofac Surg 2003; 31:51-61.

2. Kommers SC, van den Bergh B, Forouzanfar T. Quality of life after open versus closed treatment for mandibular condyle fractures: a review of literature. J Craniomaxillofac Surg 2013;41:221-5.

3. Vajgel A, de Santana Santos T, Camargo IB, Moraes de Oliveira D, Filho JR, de Holanda Vasconcellos RJ. Management of subcondylar fracture by intraoral approach. J Craniofac Surg 2013;24:587-8.

4. Kang DH. Surgical management of a mandible subcondylar fracture. Arch Plast Surg 2012;39:284-90.

5. Ellis E III. Complications of mandibular condyle fractures. Int J Oral Maxillofac Surg 1998;27:255-7.

6. Hakim SG, Wolf M, Wendlandt R, Kimmerle H, Sieg P, Jacobsen HC. Comparative biomechanical study on three miniplates osteosynthesis systems for stabilisation of low condylar fractures of the mandible. Br J Oral Maxillofac Surg 2014;52:317-22.

7. Danda AK, Muthusekhar MR, Narayanan V, Baig MF SA. Open versus closed treatment of unilateral subcondylar and condylar neck fractures: a prospective, randomized clinical study. J Oral Maxillofac Surg 2010;68:1238-41.

8. Sforza C, Ugolini A, Sozzi D, Galante D, Mapelli A BA. Three dimensional mandibular motion after closed and open reduction of unilateral mandibular condylar process fractures. J Craniomaxillofacial Surg 2011;39:249-55.

9. Al-Moraissi EA, Ellis E. Surgical treatment of adult mandibular condylar fractures provides better outcomes than closed treatment: a systematic review and meta-analysis. J Oral Maxillofac Surg 2015;73:482-93.

10. Throckmorton, Gaylord S. Dechow, Paul C. In vitro strain measurements in the condylar process of the human mandible. Arch Oral Biol 1994;39:853-67.
11. Meyer C1, Kahn JL, Boutemi P, Wilk A. Photoelastic analysis of bone deformation in the region of the mandibular condyle during mastication. J Craniomaxillofac Surg 2002; 30:160-9.

12. Lauer G1, Haim D, Proff P, Richter G, Pradel W, Fanghänel J, et al. Plate osteosynthesis of the mandibular condyle. Ann Anat 2007;189:412-7.

13. Frerich, B. Seemann, R. Wagner, A. Piffko, J.. Locking versus non locking miniplate osteosynthesis of mandibular fractures - Preliminary results. J Craniomaxillofac Surg 2006;34:113-6.

14. Ashor M, Salah A, Shindy M, Selim H, Metwaly S, Behairy G. Clinical and radiographic outcomes of rhomboid plate in management of subcondylar fractures: prospective randomized controlled trial. Egypt J Oral Maxillofac Surg 2018;9:1-5.

15. Kozakiewicz M, Swiniarski J. "a" shape plate for open rigid internal fixation of mandible condyle neck fracture. J Cranio-Maxillofacial Surg 2014;42:730-7.

16. Zide MF, Kent JN. Indications for open reduction of mandibular condyle fractures. J Oral Maxillofac Surg 1983;41:89-98.

17. Conti AC1, Oltramari PV, Navarro Rde L, de Almeida MR. Examination of temporomandibular disorders in the orthodontic patient: a clinical guide. J Appl Oral Sci 2007; 15:77-82.

18. Jensen MP, Chen C, Brugger Am. Interpretation of visual analog scale ratings and change scores. J Pain 2003; $4: 407-14$

19. Schmitter M, Ohlmann B, John MT, Hirsch C, Rammelsberg P. Research diagnostic criteria for temporomandibular disorders: A calibration and reliability study. Cranio 2005;23:212-8.

20. John MT1, Hirsch C, Reiber T DS. Translating the research diagnostic criteria for temporomandibular disorders into German: Evaluation of content and process. J Orofac Pain 2006;20:43-52.

21. Veras RB, Kriwalsky MS, Eckert AW, Schubert J, Maurer P. Long-Term Outcomes After Treatment of Condylar Fracture by Intraoral Access: A Functional and Radiologic Assessment. J Oral Maxillofac Surg 2007;65:1470-6.

22. House JW, Brackmann DE. Facial nerve grading system. Otolaryngol Head Neck Surg 1985;93:146-7. 
23. Alicandri-Ciufelli M, Pavesi G PL. Facial nerve grading scales: systematic review of the literature and suggestion for uniformity. Plast Reconstr Surg 2015;135:929-30.

24. Borstlap WA1, Stoelinga PJ, Hoppenreijs TJ van't HM. Stabilisation of sagittal split advancement osteotomies with miniplates: A prospective, multicentre study with two-year follow-up. Part III - Condylar remodelling and resorption. Int J Oral Maxillofac Surg 2004;33:649-55.

25. Singh V, Kumar N, Bhagol A, Jajodia N. A Comparative Evaluation of Closed and Open Treatment in the Management of Unilateral Displaced Mandibular Subcondylar Fractures: A Prospective Randomized Study. Craniomaxillofac Trauma Reconstr 2018;11:205-10.

26. Pereira-Filho V, Welsh B, Schübel F, Landes C, Sader R, Gabrielli M, Monnazzi M. Intraoral Approach for Treatment of Displaced Condylar Fractures: Case Report. Craniomaxillofacial Trauma Reconstr 2011;4:107-12.

27. Choi BH, Yoo JH. Open reduction of condylar neck fractures with exposure of the facial nerve. Oral Surg Oral Med Oral Pathol Oral Radiol Endod 1999;88:292-6.

28. Sikora M, Sielski M, Stąpor A CD. Use of the Delta plate for surgical treatment of patients with condylar fractures. $\mathrm{J}$
Craniomaxillofac Surg 2016;44:770-4.

29. Haim D, Müller A, Leonhardt H, Nowak A, Richter G LG. Biomechanical study of the Delta plate and the Tri lock Delta condyle trauma plate. J Oral Maxillofac Surg 2011;69:2619-25.

30. Ellis III E, Simon P TG. Occusal Results after open or closed treatment of fractures of the mandibular condylar process. J Oral Maxillofac Surg 2000;58:260-8.

31. Shi D, Patil PM, Gupta R. Facial nerve injuries associated with the retromandibular transparotid approach for reduction and fixation of mandibular condyle fractures. $\mathrm{J}$ Cranio-Maxillofacial Surg 2015;43:402-7.

32. Bhutia O, Kumar L, Jose A, Roychoudhury A TA. Evaluation of facial nerve following open reduction and internal fixation of subcondylar fracture through retromandibular transparotid approach. Br J Oral Maxillofac Surg 2014;52:236-40.

33. Costa FWG, Bezerra MF, Ribeiro TR, Pouchain EC, Sabóia VDPA SE. Biomechanical analysis of titanium plate systems in mandibular condyle fractures: a systematized literature review. Acta Cir Bras 2012;27:424-9. 